\title{
Growth of columnar gold electrodes by electroreducing hydrous gold oxide layers: kinetics and mechanistic interpretation
}

\author{
M.E. Vela, S.L. Marchiano, R.C. Salvarezza, A.J. Arvia \\ Instituto de Inestigaciones Fisicoquímicas Teóricas y Aplicadas (INIFTA). Casilla de Correo 16. Sucursal 4, (1900) La Plata. Argentina
}

Received 8 July 1994; ill revised form 15 Nuvenber 1994

\begin{abstract}
Rough columnar structured gold electrodeposits were prepared in aqueous $0.5 \mathrm{M} \mathrm{H}_{2} \mathrm{SO}_{4}$ by electroreducing a hydrous gold oxide layer built up on a gold substrate by means of a fast periodic potential routine. The analysis of potentiodynamic and potentiostatic hydrous oxide layer electroreduction data indicated the initial nucleation of gold clusters at the metal $\mid$ oxide interface. The growth of gold nuclei proceeded under a constant capture area condition for depositing gold ions contained in the hydrous oxide layer. Columnar gold electrodeposition was assisted by the gel-like characteristics of the hydrous gold oxide layer. Gold columnar growth ended as soon as the column tips reached the oxide/solution interface. The proposed kinetic model accounts for the high surface area development and surface fractal properties of this type of metal electrode.
\end{abstract}

Keywords: Columnar growth; Electroreduction kinetic model

\section{Introduction}

The formation of metal electrodeposits from cither metal ions in aqueous solution or hydrous metal oxide layers on a conducting substrate, far from the equilibrium potential, can produce different types of irregular topographies. A relatively large number of physical and chemical processes are related to the growth of objects involving an irregular surface, a non-uniform mass distribution and a porous structure [1]. Under growth conditions far from equilibrium, the structure developed by these objects can be compared to diffusionlimited aggregation, dense radial or columnar-like patterns derived from computer simulations [2]. Generally, columnar-like objects with a self-affine fractal surface are formed at intermediate growth rates, i.e. $1.5 \times 10^{-6}$ $\mathrm{cm} \mathrm{s}^{-1} \leq i \leq 1.5 \times 10^{-5} \mathrm{~cm} \mathrm{~s}^{-1}$ [3]. At a high growth rate, i.e. $v>1.5 \times 10^{-5} \mathrm{~cm} \mathrm{~s}^{-1}$, branched objects with either a self-similar fractal surface or a self-similar fractal mass and surface can be obtained [2]. Generally, the development of a self-affine fractal surface can be expected when the object growth rate is dominated mainly by a surface process [4], whereas self-similar surfaces are typical of objects which are grown under a Laplacian field surrounding the growing surface, such as those produced by an electric potential or a concentration gradient $[4,5]$.

The growth of columnar-structured gold deposits resulting from the electroreduction of a hydrous gold oxide layer is investigated in this paper. This kinetic study is based on the potentiostatic current transients and potentiodynamic current-potential curves for the electroreduction process, combined with scanning electron microscopy (SEM) and scanning tunnelling microscopy (STM) imaging.

\section{Experimental}

\subsection{The electrochemical cell}

The electrochemical cell consisted of the working electrode, a large gold plate counter-electrode, and a $\mathrm{Hg}\left|\mathrm{Hg}_{2} \mathrm{SO}_{4}\right| 0.5 \mathrm{M} \mathrm{H}_{2} \mathrm{SO}_{4}$ reference electrode immersed in aqueous $0.5 \mathrm{M} \mathrm{H}_{2} \mathrm{SO}_{4}$. Potentials in the text are referred to the standard hydrogen electrode (SHE). In this work gold wire electrodes $(99.99 \%$ purity, ca. $0.2 \mathrm{~cm}^{2}$ exposed area) were used as working electrodes. The gold wires were first electropolished in aqueous 8 
$\mathrm{M} \mathrm{H}_{2} \mathrm{SO}_{4}$ by applying $10-15 \mathrm{~V}$ ac at $50 \mathrm{kHz}$, and then repetitively rinsed with Milli-Q ${ }^{*}$ water.

The preparation of the hydrous gold oxide layer, its electroreduction yielding the columnar structured gold overlayer and the evaluation of the real surface area were performed in the same electrochemical cell.

\subsection{Preparation of the hydrous gold oxide layer}

Hydrous gold oxide layers were prepared by applying to the electropolished gold electrode a periodic symmetric square-wave potential routine (SWPR) between a lower $\left(E_{1}=0.45 \mathrm{~V}\right)$ and an upper $\left(E_{\mathrm{u}}=2.7 \mathrm{~V}\right)$ potential at a frequency $f=5 \mathrm{kHz}$ for variable times $\tau$ (10 $\mathrm{s} \leq \tau \leq 420 \mathrm{~s})$ to accumulate different amounts of oxide on the substrate. Details of the hydrous gold oxide preparation technique have been described extensively elsewhere [6]. Prior to its electroreduction, the oxide-covered gold electrode was kept in the cell at $1.5 \mathrm{~V}$ for $1 \mathrm{~min}$ under $\mathrm{N}_{2}$ bubbling to eliminate traces of $\mathrm{O}_{2}$ which could be produced simultaneously with the oxide layer at $E_{\mathrm{u}}$.

\subsection{Electroformation of the gold overlayer}

The hydrous gold oxide layer was electroreduced to produce the columnar gold overlayer by applying either a linear potential scan from 1.5 to $0.05 \mathrm{~V}$ at different sweep rates in the range $3 \times 10^{-4} \mathrm{~V} \mathrm{~s}^{-1} \leq v \leq 0.3$ $\mathrm{V} \mathrm{s}^{-1}$, or a potential step from $E_{0}=1.5 \mathrm{~V}$ to $E_{\mathrm{s}}(0.05$ $\left.\mathrm{V} \leq E_{\mathrm{s}} \leq 0.95 \mathrm{~V}\right)$. The apparent oxide electroreduction charge density $q_{\mathrm{r}}$ measured from either the apparent current density $j$ versus potential $E$ profile resulting from a linear potential sweep or the potentiostatic current transient was taken as a measure of the amount of hydrous gold oxide produced on the working electrode [7].

The electrochemical reduction experiments were performed in aqueous $0.5 \mathrm{M} \mathrm{H}_{2} \mathrm{SO}_{4}$ and, occasionally, in $0.05 \mathrm{M}$ aqueous $\mathrm{H}_{2} \mathrm{SO}_{4}$.
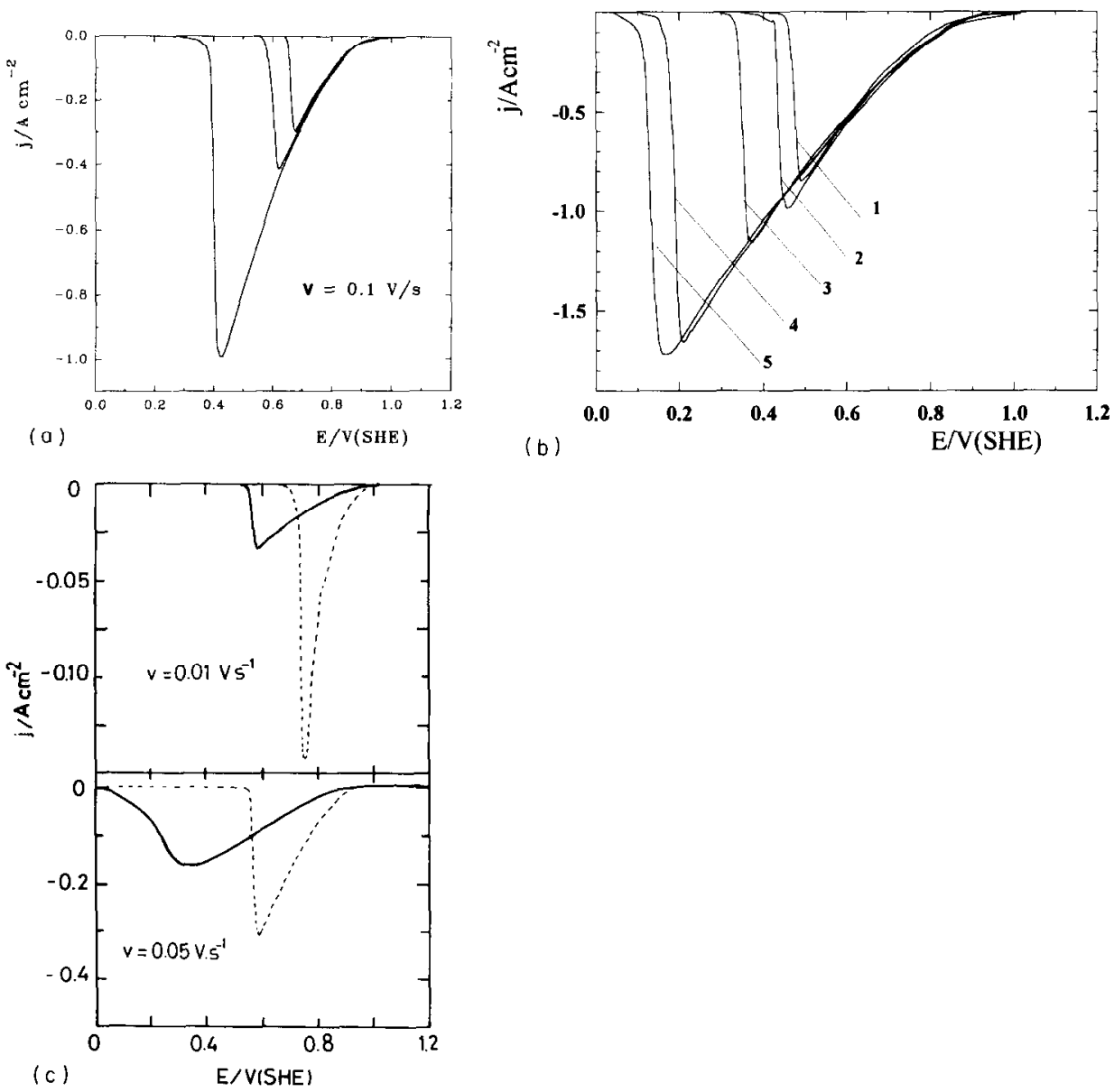

Fig. 1. (a) Single linear potential sweep electroreduction of hydrous gold oxide layers in $0.5 \mathrm{M} \mathrm{H}_{2} \mathrm{SO}_{4}$ at $v=0.1 \mathrm{~V} \mathrm{~s}^{-1}$ and $25^{\circ} \mathrm{C}$ : (1) $q_{\mathrm{r}}=1.98 \mathrm{C}$. $\mathrm{cm}^{-2}$; (2) $q_{\mathrm{r}}=0.69 \mathrm{C} \mathrm{cm}^{-2}$; (3) $q_{\mathrm{r}}=0.36 \mathrm{C} \mathrm{cm}^{-2}$. (b) Single linear potential sweep electroreduction of hydrous gold oxide layers $\left(q_{\mathrm{r}}=1.8 \pm 0.1\right.$ $\mathrm{C} \mathrm{cm}^{-2}$ ) in $0.5 \mathrm{M} \mathrm{H}_{2} \mathrm{SO}_{4}$ at $25^{\circ} \mathrm{C}$ : (1) $v=0.075 \mathrm{~V} \mathrm{~s}^{-1}$; (2) $v=0.10 \mathrm{~V} \mathrm{~s}^{-1}$; (3) $v=0.15 \mathrm{~V} \mathrm{~s}^{-1}$; (4) $v=0.25 \mathrm{~V} \mathrm{~s}^{-1}$; (5) $v=0.30 \mathrm{~V} \mathrm{~s}-1$. (c) Influence of the $\mathrm{H}_{2} \mathrm{SO}_{4}$ concentration on the voltammetric electroreduction of hydrous oxide gold layers which have been prepared in $0.5 \mathrm{M}$ $\mathrm{H}_{2} \mathrm{SO}_{4}$ at $25^{\circ} \mathrm{C}$ : ( $) 0.05 \mathrm{M} \mathrm{H}_{2} \mathrm{SO}_{4}$; (- - -$) 0.5 \mathrm{M} \mathrm{H}_{2} \mathrm{SO}_{4}$. 


\subsection{Real surface area measurement}

The real surface area of the columnar gold overlayer was expressed by the roughness factor $R$, defined as $R=Q_{\mathrm{f}} / Q_{\mathrm{i}}$ where $Q_{\mathrm{f}}$ and $Q_{\mathrm{i}}$ are the $\mathrm{O}$ electrodesorption voltammetric charges measured for the columnar gold overlayer and the gold electrode before the preparation of the hydrous gold oxide layer [6-8]. By changing $\tau$, and hence $q_{\mathrm{r}}$, the value of $R$ could be varied in the range $3 \leq R \leq 100$.

\section{Results}

\subsection{Voltammetric data}

The $j$ vs. $E$ profiles related to the potentiodynamic electroreduction of hydrous gold oxide layers in aqueous $0.5 \mathrm{M} \mathrm{H}_{2} \mathrm{SO}_{4}$ were run either at constant $v$ and different $q_{\mathrm{r}}$, or at constant $q_{\mathrm{r}}$ and different $v$.

Those profiles obtained at constant $v$ and different $q_{\mathrm{r}}$ (Fig. 1 (a)) are very asymmetric. Initially, a non-linear increase in $j$ with $E$ can be observed, irrespective of the $q_{\mathrm{r}}$ value. Then the current reaches a maximum value $j_{\mathrm{p}}$ and finally, as the electroreduction of the oxide layer is almost complete, it decreases rather sharply to nearly zero. In addition, as $q_{\mathrm{r}}$ increases, $j_{\mathrm{p}}$ also increases, and the potential $E_{\mathrm{p}}$ related to $j_{\mathrm{p}}$ shifts to more negative values.

In contrast, data resulting from those runs made at a constant $q_{\mathrm{r}}$ and different $v$ (Fig. 1(b)), yield linear $i_{\mathrm{p}}$ vs. $l^{1 / 2}$ and $E_{\mathrm{p}}$ vs. $v^{1 / 2}$ plots (Fig. 2), as expected for an electrochemical process involving an ohmic overvoltage contribution [9]. It should be noted that relatively large electroreduction currents, typically of the order of $0.1 \mathrm{~A}$, are involved in this work (Fig. 1(a)), in contrast with the electrochemical reduction currents of multilayer oxides on smooth metal surfaces [10].

Similar runs were made for oxide layers formed in aqueous $0.5 \mathrm{M} \mathrm{H}_{2} \mathrm{SO}_{4}$ and subsequently electroreduced in aqueous $0.05 \mathrm{M} \mathrm{H}_{2} \mathrm{SO}_{4}$. In these case, the $j$ vs. $E$ profiles (Fig. 1(c)) show that the initial non-linear current increase is restricted to a smaller potential range than that in aqueous $0.5 \mathrm{M} \mathrm{H}_{2} \mathrm{SO}_{4}$, and it is followed by a nearly linear current increase which covers the range $0.8-0.4 \mathrm{~V}$, at least for those runs made at $0.05 \mathrm{~V} \mathrm{~s}^{-1}$.

According to these results, it is clear that the electrochemical reduction of thick oxide layers under the conditions of our experiments involves an ohmic resistance contribution which can be enhanced by increasing the resistance of the electrolyte solution. The ohmic polarization contribution to the kinetics of the reaction becomes more significant as $v$ is increased, i.e. as the electrochemical reduction current increases (Fig. 1(b)).

\subsection{Potentiostatic electroreduction current transients}

Potentiostatic electroreduction current transients for constant $q_{\mathrm{r}}$ were made by stepping the potential from $E_{0}=1.5 \mathrm{~V}$ to $E_{\mathrm{s}}\left(0.05 \mathrm{~V} \leq E_{\mathrm{b}} \leq 0.95 \mathrm{~V}\right)$. Transient electroreduction responses can be interpreted in terms of two distinct phenomena, namely the initial fast electroreduction of an inner $\mathrm{O}$-atom-containing monolayer, followed by the electroreduction of the thick outer oxide overlayer [11]. The first contribution appears in the short time range as an initially decreasing current. When the electroreduction takes place at relatively low rates in the range $0.90 \mathrm{~V}<E_{\mathrm{c}}<0.95 \mathrm{~V}$, the second contribution involves an initial current increase up to a current maximum value and then a decrease to nearly zero (Fig. 3 ). The current maximum increases as $E_{\mathrm{s}}$ moves in the negative direction. obeying a Tafel relationship with a slope close to $0.120 \mathrm{~V}$ decade $^{-1}$. The shape of these transients and the potential dependence of the current maximum are consistent with a phase change involving three-dimensional nucleation and growth under charge transfer control [11]. The irreversibility of this process should be related to the presence of an electrocrystallization overvoltage [12]. Under these conditions a compact gold overlayer with $R<3$ is ubtained [11].

In contrast, as $E_{\mathrm{s}}$ is shifted negatively the potentiostatic current maximum becomes a plateau. This situation, which involves the electroreduction of thick hydrous oxide layers at high negative overvoltages, is the focal point of this work because it facilitates the pro-

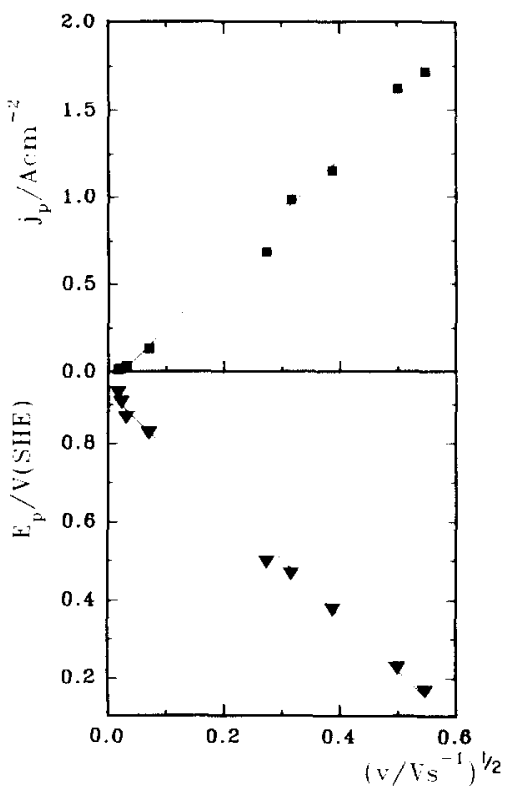

Fig. 2. Plots of current peak $j_{\mathrm{p}}$ vs. $l^{1 / 2}$ and peak potential $E_{\mathrm{p}}$ vs. $\imath^{1 / 2}$ from a single linear potential sweep for hydrous gold oxide electroreduction voltammograms run at different values of $1.10 .5 \mathrm{M}$ $\mathrm{H}_{2} \mathrm{SO}_{4} ; 25^{\circ} \mathrm{C}$. 


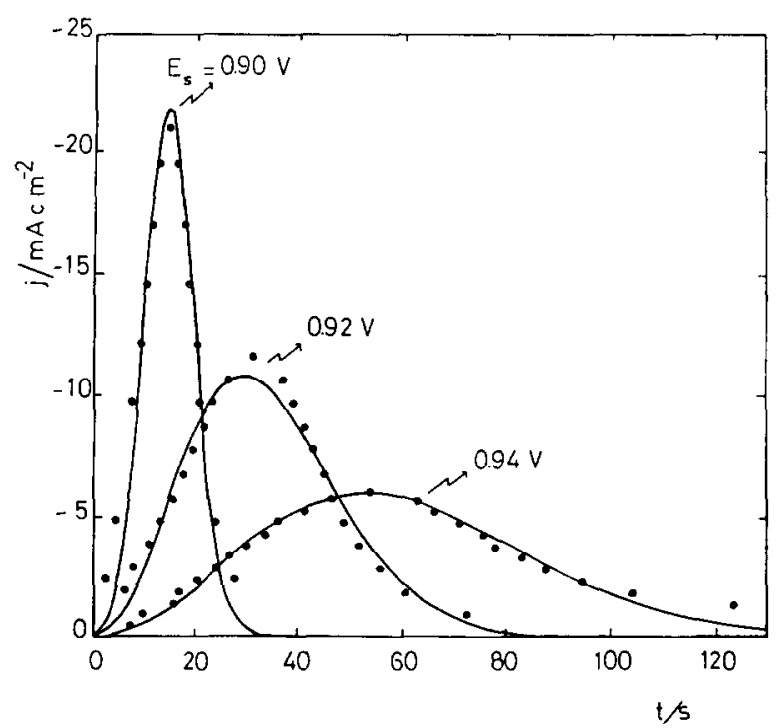

Fig. 3. Electroreduction current transients at different $E_{\mathrm{s}}$ in $0.5 \mathrm{M}$ $\mathrm{H}_{2} \mathrm{SO}_{4}$ at $25^{\circ} \mathrm{C}: \bullet$ experimental data; ( $\longrightarrow$ ) data from the threedimensional nucleation and growth model with the death of growing centers.
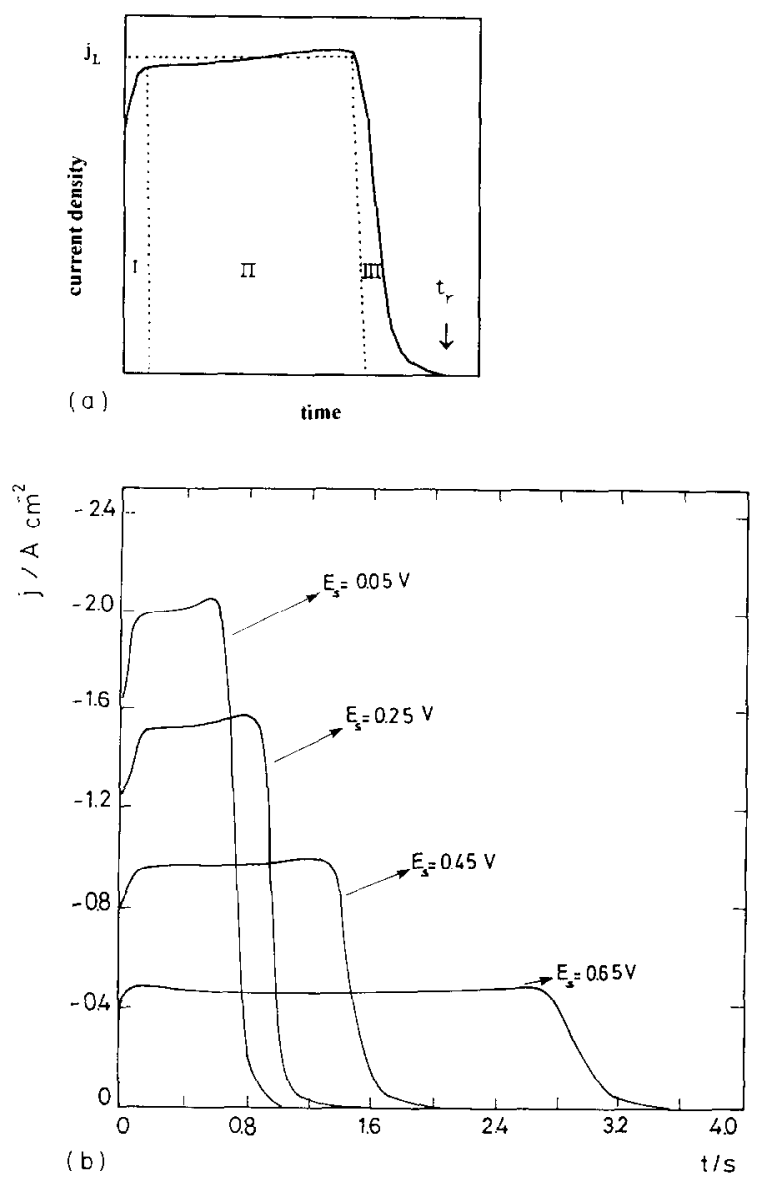

Fig. 4. (a) A typical thick hydrous gold oxide layer potentiostatic electroreduction current transient for $E_{\mathrm{s}}<0.9 \mathrm{~V}$. Regions I, II and III are described in the text. (b) Hydrous gold oxide layer $\left(q_{\mathrm{r}}=1.5 \mathrm{C}\right.$ $\mathrm{cm}^{2}$ ) potentiostatic current transients run at different $E_{\mathrm{s}}$ values $\left(0.5 \mathrm{M} \mathrm{H}_{2} \mathrm{SO}_{4} ; 25^{\circ} \mathrm{C}\right)$.

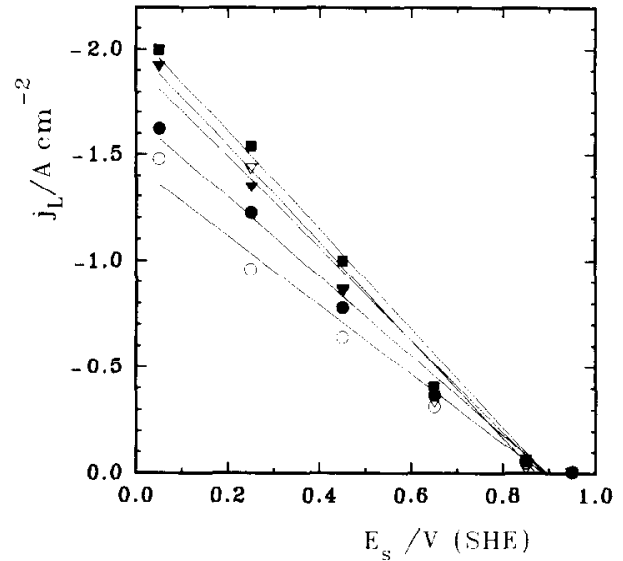

Fig. 5. Plot of plateau current $j_{\mathrm{L}}$ vs. $E_{\mathrm{s}}$ resulting from hydrous gold oxide electroreduction voltammograms involving different $q_{\mathrm{r}}$ values $\left(0.5 \mathrm{M} \mathrm{H}_{2} \mathrm{SO}_{4} ; 25^{\circ} \mathrm{C}\right): 0.45 \mathrm{C} \mathrm{cm}^{-2} ; \nabla 0.75 \mathrm{C} \mathrm{cm}^{-2} ; \nabla 1.15 \mathrm{C}$ $\mathrm{cm}^{-2} ; \bullet 1.37 \mathrm{C} \mathrm{cm}^{-2} ; 01.9 \mathrm{C} \mathrm{cm}^{-2}$.

duction of columnar structured large surface area metal electrodes of electrocatalytic interest. In this case, potentiostatic current transients (Fig. 4(a)) show an initial current increase in region $I$, followed by a nearly constant current density $j_{L}$ in region II and a sudden current decay to zero in region III.

A sequence of experiments involving the same value of $q_{\mathrm{r}}$ but different $E_{\mathrm{s}}$ showed that $j_{\mathrm{L}}$ increases as $E_{\mathrm{s}}$ is negatively shifted (Fig. 4(b). For $E_{\mathrm{s}}<0.8 \mathrm{~V}$, a linear $j_{\mathrm{L}}$ vs. $E_{\mathrm{s}}$ relationship can also be observed (Fig. 5). At constant $E_{\mathrm{s}}$ the value of $j_{\mathrm{L}}$ decreases slightly as $q_{\mathrm{r}}$ is increased.

Similar electroreduction current transients were run at $E_{\mathrm{s}}=0.25 \mathrm{~V}$ and $q_{\mathrm{r}}$ values in the range $0.475 \mathrm{C}$ $\mathrm{cm}^{-2} \leq q_{\mathrm{r}} \leq 1.75 \mathrm{C} \mathrm{cm}^{-2}$ (Fig. 6). For constant $E_{\mathrm{s}}, j_{\mathrm{L}}$ decreases slightly as $q_{\mathrm{r}}$ is increased, suggesting some contribution of the oxide resistivity to the overall electroreduction rate. Similar trends were observed in experiments performed in aqueous $0.05 \mathrm{M} \mathrm{H}_{2} \mathrm{SO}_{4}$.

Values of $j_{\mathrm{L}}$ resulting from runs involving different values of $q_{\mathrm{r}}$ for both aqueous solutions are assembled in Table 1. Values of $j_{\mathrm{L}}$ and $j_{\mathrm{L}} / q_{\mathrm{r}}$ at constant $E_{\mathrm{S}}$ decrease proportionally to the specific conductance $\kappa$ of the electrolyte solution (Table 1).

Table 1

Comparison of current densities $j_{\mathrm{L}}$ corresponding to different gold oxide charges obtained in aqueous $0.5 \mathrm{M} \mathrm{H}_{2} \mathrm{SO}_{4}$ and electroreduced potentiostatically at $E_{\mathrm{s}}=0.25 \mathrm{~V}$ in $0.5 \mathrm{M} \mathrm{H}_{2} \mathrm{SO}_{4}$ and $0.05 \mathrm{M} \mathrm{H}_{2} \mathrm{SO}_{4}$

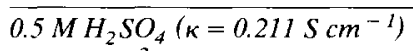

\begin{tabular}{lllll}
$q_{\mathrm{r}} / \mathrm{C} \mathrm{cm}^{-2}$ & 0.45 & 0.79 & 1.13 & 1.41 \\
$j_{\mathrm{L}} / \mathrm{A} \mathrm{cm}^{-2}$ & 1.81 & 1.73 & 1.67 & 1.47 \\
$\left(j_{\mathrm{L}} / q_{\mathrm{r}}\right) / \mathrm{s}^{-1}$ & 4.02 & 2.18 & 1.47 & 1.04 \\
$0.05 \mathrm{M} \mathrm{H}_{2} \mathrm{SO}_{4}\left(\kappa=0.0243 \mathrm{S \textrm {cm } ^ { - 1 } )}\right.$ & & & & \\
$q_{\mathrm{r}} / \mathrm{C} \mathrm{cm}^{-2}$ & 0.37 & 0.58 & 0.85 & 1.07 \\
$j_{\mathrm{L}} / \mathrm{A} \mathrm{cm}^{-2}$ & 0.25 & 0.19 & 0.19 & 0.19 \\
$\left(j_{\mathrm{L}} / q_{\mathrm{r}}\right) / \mathrm{s}^{-1}$ & 0.67 & 0.33 & 0.22 & 0.18 \\
\hline
\end{tabular}




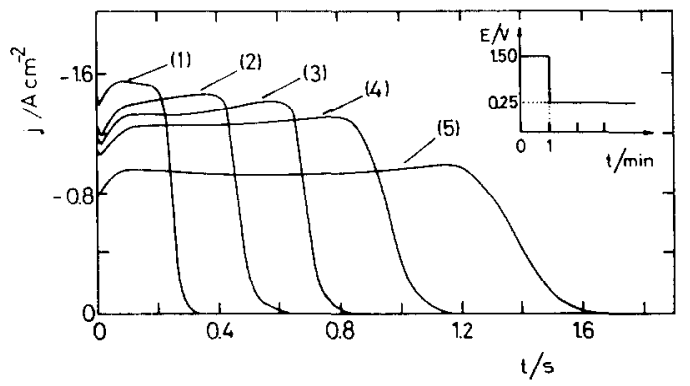

Fig. 6. Potentiostatic current transients for the electroreduction of a thick hydrous gold oxide layer at $E_{\mathrm{S}}=0.25 \mathrm{~V}\left(0.5 \mathrm{M} \mathrm{H}_{2} \mathrm{SO}_{4} ; 25^{\circ} \mathrm{C}\right)$ : (1) $q_{\mathrm{r}}=0.47 \mathrm{C} \mathrm{cm}^{-2}$; (2) $q_{\mathrm{r}}=0.84 \mathrm{C} \mathrm{cm}^{-2}$; (3) $q_{\mathrm{r}}=1.2 \mathrm{C} \mathrm{cm}^{-2}$; (4) $q_{\mathrm{r}}=1.5 \mathrm{C} \mathrm{cm}^{-2} ;(5) q_{\mathrm{r}}=1.75 \mathrm{C} \mathrm{cm}^{-2}$.

From the analysis of the potentiostatic electrochemical reduction data it can be concluded that, for a particular solution, the value of $j_{\mathrm{L}}$ is slightly dependent on $q_{\mathrm{r}}$, but strongly dependent on the specific conductance of the solution. Therefore the kinetics of the process is mainly governed by the solution resistance rather than the oxide layer resistance.

\subsection{SEM and STM imaging}

The cross-section of gold electrodeposits resulting from these experiments reveals elongated grains which are consistent with a rough columnar structured elec1rodeposit (Fig. 7) involving a void-to-mass ratio which does not change appreciably along the deposit thickness.

STM images reveal that these electrodeposits are made of rounded elements which correspond to gold column tips (Fig. 8). The average electrodeposit columnar radius $r$, measured from STM images [13], increases with $\delta$ according to a $r \propto \delta^{p}$ relationship with $p \approx 0.25$ (Fig. 9), i.e. the average columnar radius is slightly dependent on the electrodeposit thickness [13].

The fact that the columnar size is rather uniform for $\delta \Rightarrow 0$ suggests that instantancous nucleation opcrates at the very early stages of the gold electrodeposit growth. The column density $N$, estimated from the value of $r$, is in the range $10^{11}$ column $\mathrm{cm}^{-2}<N<10^{12}$ column $\mathrm{cm}^{-2}$. This means that the electrodeposit structure comprises small intercolumnar voids with an average cross-section of the order of $10^{-12} \mathrm{~cm}^{2}$.

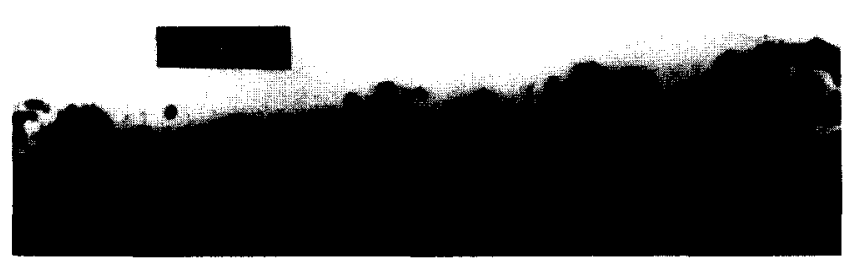

Fig. 7. SEM image of a gold overlayer cross section. Bar $=1 \mu \mathrm{m}$.

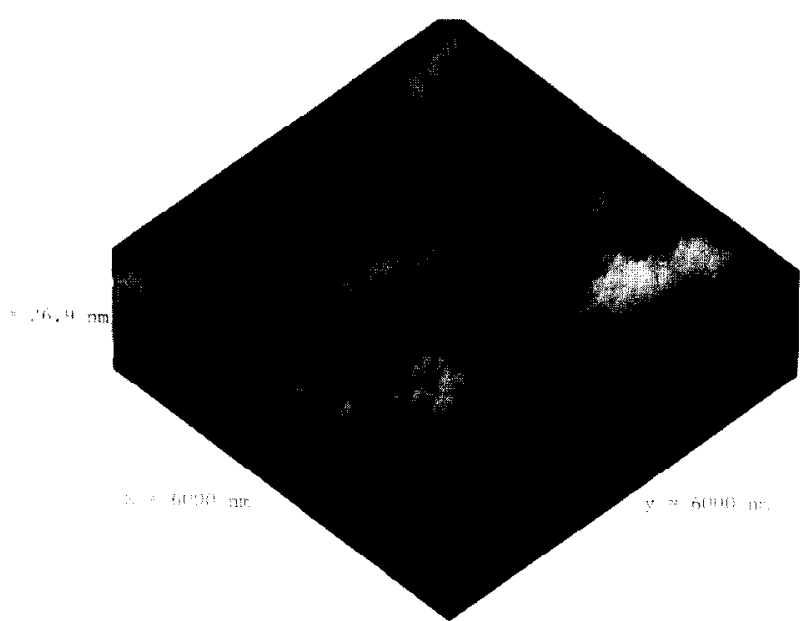

Fig. 8. Three-dimensional SIM image $(6)(h) \mathrm{nm} \times 6(1)(k) \mathrm{nm})$ of at columnar structured gold overlayer.

It is worth noting that attempts to obtain tunneling between the tip and the oxide-covered specimen and between the tip and the specimen after $30 \%$ of the oxide layer has been electroreduced were unsuccessful. This is a clear demonstration that electroreduction of the gold overlayer starts from the metal |oxide interface and proceeds outwards. Therefore the electroreduction of this type of gold oxide takes place in a different way from that proposed for multilayers of platinum oxide [10].

\subsection{Further kinetic data}

Kinetic information about the electrodeposit growth can be obtained from plots of the average electrodeposit thickness $\delta$ vs. the electroreduction time $t_{\mathrm{r}}$. As SEM images of the electrodeposit cross-section (Fig. 7) reveal a metal-to-void ratio which on average remains almost independent of the metal overlayer thickness, it

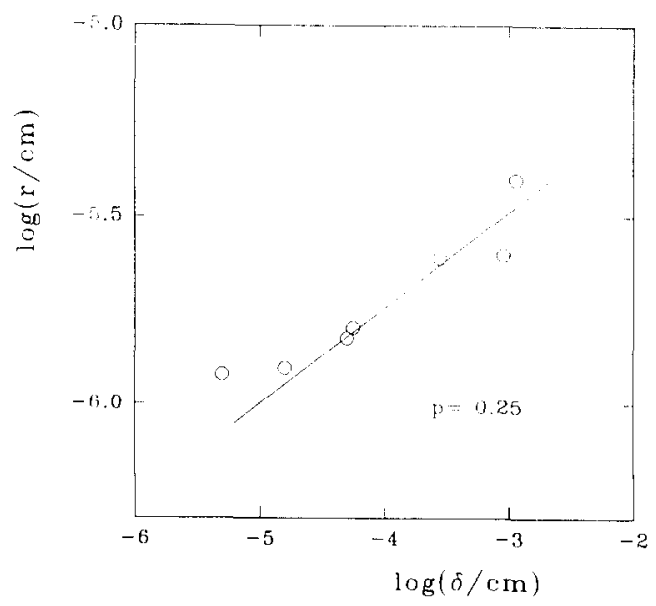

Fig. 9. Plot of $\log$ (average column tip radius $r$ ) vs. $\log$ (average gold overlayer thickness $\delta$ ) resulting from STM imaging. The slope is $p=0.25$. 
Table 2

Average growth rate $v_{\mathrm{c}}=\partial \delta / \partial t_{\mathrm{r}}$ calculated from $\delta$ vs. $t_{\mathrm{r}}$ plots for the gold column front at different $E_{\mathrm{s}}$

\begin{tabular}{lllll}
\hline$E_{\mathrm{s}} / \mathrm{V}$ & 0.65 & 0.45 & 0.25 & 0.05 \\
$10^{5} v_{\mathrm{c}} / \mathrm{cm} \mathrm{s}^{-1}$ & 1.88 & 3.82 & 5.29 & 10.5
\end{tabular}

is reasonable to assume that the apparent density $\rho$ of the electrodeposit is uniform. Thus, using the value of $\delta$ derived from the SEM imagc, $\rho$ can be cstimated from

$\delta=q_{\mathrm{r}} M / z F \rho$

where $F$ is Faraday's constant, $M$ is the molar mass of gold and $z$ is the number of electrons transferred per mole of gold. Taking $M=197 \mathrm{~mol} \mathrm{~g}^{-1}, \delta=9 \times 10^{-5}$ $\mathrm{cm}, q_{\mathrm{r}}=1.2 \mathrm{C} \mathrm{cm}^{-2}$ and $z=3[7,14]$, Eq. (1) yields $\rho=10 \mathrm{~g} \mathrm{~cm}^{-3}$, which is close to the density of gold oxide $\left(\rho=11 \mathrm{~g} \mathrm{~cm}^{-3}[15]\right)$ rather than the value of 19.3 $\mathrm{g} \mathrm{cm}^{-3}$ expected for gold. This means that the electroreduction process operates as a nearly constantvolume phase change, leading to a gold overlayer composed of about $50 \%$ gold and $50 \%$ voids.

Eq. (1) is used to estimate values of $\delta$ taking $M=442$ $\mathrm{g} \mathrm{mol}^{-1}, z=6$ and $\rho=11 \mathrm{~g} \mathrm{~cm}^{-3}$, for the gold oxide $\left(\mathrm{Au}_{2} \mathrm{O}_{3}\right)$ layer or $M=197 \mathrm{~g} \mathrm{~mol}^{-1}, z=3$ and $\rho=10 \mathrm{~g}$ $\mathrm{cm}^{-2}$ for the gold overlayer. For values of $q_{\mathrm{r}}$ in the range $0.14-10 \mathrm{C} \mathrm{cm}^{-2}$, values of $\delta$ in the range $90-6000$ $\mathrm{nm}$ are obtained. No significant changes in $\delta$ are found when sets of parameters for other stoichiometries of gold oxide layer electrochemical reduction are chosen, as all of them lead to a value of $M / z \rho$ in the range $5.9-6.2[16]$.

The $\delta$ vs. $t_{\mathrm{r}}$ plot exhibits linear behaviour, and the slope $v_{c}$ of this line can be assigned to the average rate of advance of the gold column front. Furthermore, $v_{\mathrm{c}}$ increases as $E_{\mathrm{s}}$ is negatively shifted (Fig. 10 and Table

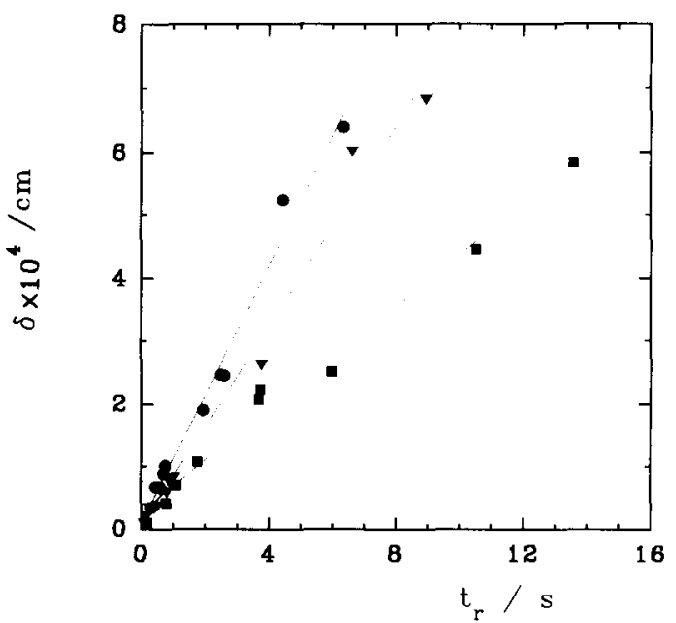

Fig. 10. Average gold overlayer thickness $(\delta)$ vs electroreduction time $\left(\mathrm{t}_{\mathrm{r}}\right)$ plots for different $E_{\mathrm{s}}$ values. $(\bullet) E_{\mathrm{s}}=0.05 \mathrm{~V} ;(\nabla) E_{\mathrm{s}}=0.25 \mathrm{~V}$; (ש) $E_{\mathrm{s}}=0.45 \mathrm{~V}$
2) to attain the limiting value $v_{\mathrm{c}} \approx 1 \times 10^{-4} \mathrm{~cm} \mathrm{~s}^{-1}$. It should be noted that attempts to fit experimental data to a $\delta$ vs. $t_{\mathrm{r}}^{1 / 2}$ relationship led to a poor linear correlation. Accordingly, a diffusion-controlled process for the columnar growth should be discarded in principle.

\section{Discussion}

\subsection{The overall electrochemical reduction}

The overall hydrous gold oxide layer electroreduction can be represented as follows:

$$
\begin{aligned}
& {\left[\mathrm{Au}_{n}^{3+}\left(3 e^{-}\right)\right]+\left\{\mathrm{Au}(\mathrm{OH})_{3}+\mathrm{H}_{2} \mathrm{O}\right\}+3 \mathrm{H}^{+}+3 \mathrm{e}^{-}} \\
& \quad \rightarrow\left[\mathrm{Au}_{n+1}^{3+}\left(3 \mathrm{e}^{-}\right)\right]+4 \mathrm{H}_{2} \mathrm{O}
\end{aligned}
$$

where the square brackets and braces denote the gold and gold hydrous oxide phases respectively. Reaction (2) involves the simultaneous transfer of gold ions from the hydrous oxide phase to the metal phase, inward transport of protons through the hydrous oxide layer to neutralize $\mathrm{OH}^{-}$ions which constitute the hydrous oxide phase itself and water molecule diffusion.

The low rate electroreduction of hydrous oxide layers as expressed by Eq. (2) obeys a nucleation and three-dimensional growth mechanism, leading to compact deposits [11]. This kinetic behaviour is reflected in rather sharp voltammetric current peaks, particularly in those experiments run at very low potential scan rates, and potentiostatic current transients which exhibit a current potential maximum (Fig. 3), in agreement with the theory of Armstrong et al. [17]. This type of kinetics has already been discussed for the electroreduction of hydrous platinum oxide layers [18].

In contrast, the high rate of hydrous gold oxide layer electroreduction leading to gold columnar topographies (Fig. 11), which is the main concern of this work, involves a limiting growth rate of the column front (Fig. 4). Under these circumstances the initial contribution of three-dimensional nucleation and growth to the high rate electroreduction reaction operates within a short time range. Then the kinetics of the reaction are largely masked by a significant ohmic polarization due to the proper resistance of the entire system, and further column growth proceeds under an almost constant capture area. At this stage, it is possible to reproduce the voltammetric hydrous gold oxide layer electrochemical reduction in both aqueous $0.5 \mathrm{M}$ and $0.05 \mathrm{M}$ $\mathrm{H}_{2} \mathrm{SO}_{4}$ by considering the rate equation,

$j(t)=q_{\mathrm{r}}(\mathrm{d} x / \mathrm{d} t)=-K \exp \left\{-\left[\eta_{\mathrm{c}}(t)+\eta_{\mathrm{r}}(t)\right] / b_{\mathrm{c}}\right\}$

where $j(t)$ is the instantaneous apparent electroreduction current density, $q_{\mathrm{r}}$ is the complete electroreduction apparent charge density, $\eta_{\mathrm{c}}(t)=\left(E_{0}-v t\right)-E_{\mathrm{r}}$ is 
the instantaneous cathodic activation overpotential, $E_{0}$ is the initial electroreduction potential, $E_{\mathrm{r}}=1.45 \mathrm{~V}$ is the reversible potential for reaction (2) [11], $\eta_{\mathrm{r}}(t)$ is the total instantaneous ohmic overpotential, $b_{c}$ is the Tafel slope of the cathodic reaction [11] and $K$ is the pre-exponential term which involves all potential-independent parameters. In addition.

$x=\left[\delta_{0}-\delta(t)\right] / \delta_{0}$

where $\delta_{0}$ and $\delta(t)$ are the average final height and the instantaneous height of the gold electrodeposit respectively, and

$\eta_{\mathrm{r}}(t)=\eta_{\mathrm{r}, 0}(t)+\eta_{\mathrm{r}, 1}(t) x$

i.e. it is the sum of $\eta_{\mathrm{r}, 0}(t)$, the ohmic drop due to the electrolyte solution resistance $R_{0}$, and $\eta_{\mathrm{r}, 1}(t)$, the instantaneous ohmic drop resulting from the resistance $R_{1}$ of the gold oxide layer. At high electroreduction rates Eq. (3) is dominated by the exponential term, and it reproduces the shape of experimental voltammograms (Fig. 1(a)) using the experimental apparent charge density $q_{\mathrm{r}}, K=2.8 \times 10^{9} \mathrm{~A} \mathrm{~cm}^{-2}, b_{\mathrm{c}}-0.120 \mathrm{~V}$ decade $^{-1}, R_{0}=2 \Omega$ and $R_{1}=0.1 \Omega$ (Fig. 12).

\subsection{Electrochemical formation of the columnar structure}

Columnar structured electrodeposited gold overlayers prepared far from equilibrium conditions are to some extent comparable to vapour-deposited gold films [19] as they exhibit an essentially similar structure. The main difference between them appears in the value of

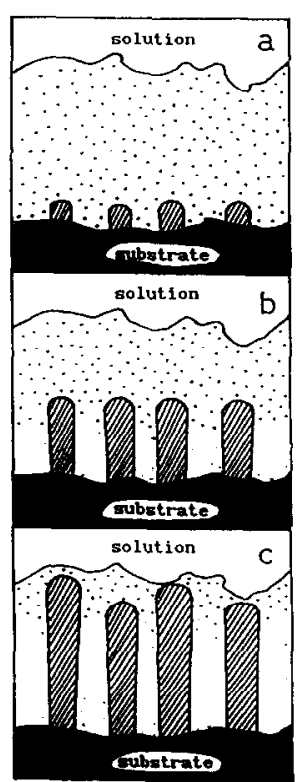

Fig. 11. Scheme of the three different stages in the electroreduction of the hydrous gold oxide layer, leading to a columnar gold overlayer. Black dots represent gold ions in the gold oxide layer; striped columns correspond to the growing gold overlayer.

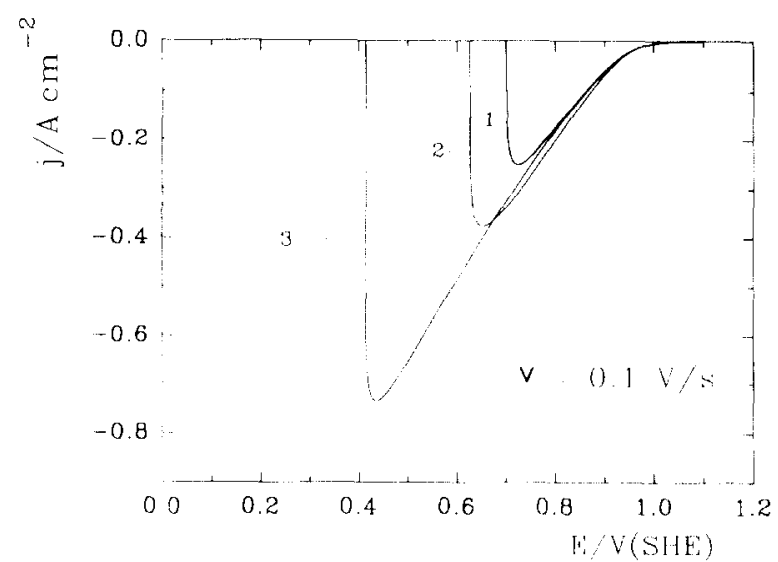

Fig. 12. Simulated electroreduction curves at $r=0.1 \mathrm{Vs}{ }^{1}$ using Eq. (3) (see text) for different values of $g_{\mathrm{r}}:$ (1) $1.98 \mathrm{C} \mathrm{cm}^{2}$; (2) $0.70 \mathrm{C}$ $\mathrm{cm}^{-2}:$ (3) $0.36 \mathrm{C} \mathrm{cm}^{-2}$.

$R$ which is in the range $1<R<1000$ for electrodeposited gold overlayers as expected for a columnar structure with deep voids, in contrast with vapour-deposited gold films for which the value of $R$ is in the range $1<R<3[19]$ as in this case intercolumnar voids penetrate only a few nanometres from the deposit surface. This difference can be attributed to a distinct growth mechanism related to the formation of either electrodeposited or vapour-deposited gold overlayers. Then, from the analysis of the preceding mechanistic data, an interpretation of the electrochemical formation of columnar gold electrodeposits can be advanced on the basis of models recently proposed for the growth of a new phase far from equilibrium conditions [1].

The appearance of a columnar structured gold deposit through reaction (2) can be interpreted in terms of competitive growth among gold nuclei (shadowing effect) leading to a fluctuating surface profile [1]. Accordingly, as a large density of three-dimensional nuclei are formed and continue growing, gold ions at internuclear voids of average area $10^{-12} \mathrm{~cm}^{2}$ disappear, and these voids, which are depleted of gold ions, cannot be replenished by ions coming from the rest of the bulk oxide phase in the short electroreduction time range $(t<0.1 \mathrm{~s})$ involved in region I (Fig. 4(a)). It should be noted that this time is much shorter than the time required for the complete hydrous gold oxide electroreduction (1-2 s). Accordingly, at the early stages of gold overlayer formation, the lateral growth of nuclei is largely hindered because the concentration of gold ions at void walls approaches zero. Conversely, growth of nuclei is favoured at tips which capture gold ions whose concentration in the oxide phase is estimated at $0.02 \mathrm{~mol} \mathrm{~cm} \mathrm{~cm}^{-3}$. In this way, following formation of nuclei, column tips should grow at a nearly constant rate.

However when a gold ion becomes an adatom at the 
column tip, in the interval $t_{\mathrm{r}}$ the adatom can diffuse over the surface a distance $l_{\mathrm{s}}$ given by

$l_{\mathrm{s}}=\left(\pi D_{\mathrm{s}} t_{\mathrm{r}}\right)^{1 / 2}$

Taking $D_{\mathrm{s}}=10^{-13} \mathrm{~cm}^{2} \mathrm{~s}^{-1}$, the surface diffusion coefficient of gold atoms at $298 \mathrm{~K}[14,20]$, and $t_{\mathrm{r}}=1 \mathrm{~s}$, it follows that $l_{\mathrm{s}} \approx 10^{-6} \mathrm{~cm}$. Thus, during the oxide layer electroreduction time, the gold adatoms at the tips have only a small chance of diffusing downwards to fill large empty domains occupied by other solution constituents. Correspondingly, as adatoms remain preferentially at column tip areas, the development of a columnar-like structure is strongly favoured.

The preceding physical description of the electrodeposition of columnar gold implies that column tips penetrate the hydrous oxide phase at a constant rate. In this case, the estimated value of $v_{c}$ is in the range $10^{-6} \mathrm{~cm} \mathrm{~s}^{-1} \leq v_{c} \leq 10^{-4} \mathrm{~cm} \mathrm{~s}^{-1}$, i.e. a range in which the formation of a columnar rather than a branched electrodeposited structure is expected [3]. Growth rates of the order of $10^{-3} \mathrm{~cm} \mathrm{~s}^{-1}$ are required for branched deposits [21].

\subsection{Further aspects of the properties of columnar growth}

Further mechanistic details can be derived from data on hydrous oxide layer clcctrorcduction at constant potential, and from the rather homogeneous columnar size distribution. Accordingly, the current in region I (Fig. 4(a)) can be assigned to the initial instantaneous nucleation and three-dimensional growth under charge transfer control at the metal loxide interface (Fig. 11). When the density of nuclei reaches a limiting value in the range $10^{11}$ nuclei $\mathrm{cm}^{-2}<N<10^{12}$ nuclei $\mathrm{cm}^{-2}$, the gold overlayer grows under a constant capture area and lateral columnar growth hindrance (region II) (Fig. 11). Furthermore, the current distribution itself favours the localization of the electrochemical process at growing tips. Under these conditions, the electroreduction current remains almost constant. In fact there is a small current increase which may be due to the $r \propto \delta^{0.25}$ functionality already mentioned. This explains why $j_{\mathrm{L}}$ increases smoothly as the hydrous gold oxide layer electroreduction proceeds, as observed in potentiostatic current transients (region II) (Fig. 4).

When the oxide layer has almost disappeared, the potentiostatic current transients decay rapidly (region III) (Figs. 4 and 11), and finally approach zero smoothly because of the irregularity of the hydrous oxide thickness itself and the statistical distribution of gold column heights. Therefore a death term for columnar growth should be included in the kinetic equation for gold overlayer growth. A deterministic description of the above mechanism for the growth of the columnar gold overlayer can be obtained by expressing the cur- rent density in terms of the potentiostatic electroreduction of the hydrous gold oxide layer as follows:

$j=z F k\left(E_{\mathrm{s}}\right) A(t)$

where

$A(t)=N[\pi r(t)]^{2}$

is the gold electrodeposit area resulting from $N$ growing nuclei and $k\left(E_{\mathrm{s}}\right)$ is a potential-dependent rate constant. For region I, after the instantaneous three-dimensional nucleation, both $A(t)$ and $j$ increase as the reaction proceeds. In region II, as the lateral growth of three-dimensional nuclei is hindered, gold electrodeposition is restricted to column tips. Furthermore, at this stage $A(t)$ can be considered as a constant term because of the instantaneous nucleation, i.e. the number of columns remains constant. Accordingly, $j$ approaches an almost constant value and the slight increase in region II can be related to the increase in $r$ with $\delta$.

Finally, the exponential decay of $j$ observed in region III can be related to the decrease in $A(t)$ as the growing tips reach the oxide/solution interface. Thus this exponential decay reflects the distribution function of the column height $h$ which, for a self-affine surface, is given by $[22,23]$

$N\left(h_{\mathrm{m}}<h<h_{\mathrm{M}}\right)=N \exp (-k \Delta h)$

where $N$ is the number of columns with an average height between the heights $h_{\mathrm{m}}$ and $h_{\mathrm{M}}$ of the lowest and highest columns respectively, $\Delta h=h_{\mathrm{M}}-h$ for the range $h_{\mathrm{m}}<h<h_{\mathrm{M}}$ and $k$ is a constant which corresponds to a reciprocal of distance.

\subsection{Local and non-local effects}

The development of the columnar structured gold electrodeposit discussed in this paper includes local effects which are specific to surface rate processes, such as the charge transfer surface reaction itself, and non-local effects due to the formation of intercolumnar voids because of the slow mobility of reacting species in the environment under the electric field. Non-local effects are absent in vapour-deposited gold films, so that they have a more compact surface structure [19]. Accordingly, the composite void-column structure of this type of electrodeposit can explain not only the high active surface area that can be measured with adsorbates of a cross-section smaller than the average void cross-section, but also their fractal surface and nonfractal mass characteristics.

\section{Acknowledgements}

This work was financially supported by the Consejo Nacional de Investigaciones Científicas y Técnicas of 
Argentina (CONICET). MEV is a member of the Research Career of CIC.

\section{References}

[1] F. Family, Physica A, 168 (1990) 561, and references cited therein.

[2] B. Grier, E. Ben-Jacob, R. Clarke and L.M. Sander, Phys. Rev. Lett.. 56 (1986) 1264.

[3] B. Movchan and A.V. Demchishin, Phys. Met. Metallogr. (USSR), 28 (1969) 83

[4] G.L.M.K.S. Kahanda, X. Zou, R. Farrell and P. Wong, Phys Rev. Lett., 68 (1992) 3741.

[5] M. Matsushita in The Fractal Approach to Heterogeneous Chemistry, Wiley, New York, 1989, p. 161, and references cited therein.

[6] A.C. Chialvo, W.E. Triaca and A.J. Arvia, J. Electroanal. Chem. $171(1984) 303$.

[7] L. Vázquez, A. Bartolomé, A.M. Baró, C. Alonso, R.C. Salvarezza and A.J. Arvia, Surf. Sci., 215 (1989) 171.

18] S. Trassatti and O. Petrii, Pure Appl. Chem., 67 (1991) 711.

19] N.R. de Tacconi, A.J. Calandra and A.J. Arvia, Electrochim. Acta, 18 (1973) 571.

[10] S. Shibata, J. Electroanal. Chem., 89 (1978) 37.
[11] M.E. Vela, R.C. Salvarezza and A.J. Arvia, Electrochim. Acta. $35(1990) 117$.

[12] L.D. Burke and M.E.G. Lyons in, R. White, J.OM. Bockris and R.E. Conway (Eds.), Modern Aspects of Electrochemistry. Vol. 18, Plenum. New York, 1986, p. 169.

[13] L. Vázque7, R.C. Salvarezza. P. Ocón. P. Herrasti. J.M. Vara and A.J. Arvia, Phys. Rev. E, $49(1994) 15117$.

[14] C. Alonso, R.C. Salvarezza, J.M. Vara, A.J. Arvia, L. Vázquez, A. Bartolome and A.M. Baró. J. Electrochem. Soc. 137 (19y)) 2161.

[15] M.M Lohrengel and J.W. Schultze. Flectrochim. Act:1, ?1 (1976) 957.

[16] M.E. Vela, J.O. Zerbino and A.J. Arvia. Thin Solid Films, 233 (1993) 82 .

[17] R.D. Armstrong, M. Fleischmann and H.R. Thirsk, J. Electroanal. Chem., 11 (1966) 208.

[18] A.E. Bolzan, A.M. Castro Luna, A. Visintín, R.C. Salvareza and A.J. Arvia, Electrochim. Acta, 33 (1988) 1743.

[19] P. Herrasti, P. Ocón, R.C. Salvarezza, J.M. Vara, L. Vázquezz and A.J. Arvia, Electrochim. Acta, 37 (1992) 2209.

[20] M. Garcia. M. Gómez, R.C. Salvarezzal and A.J. Arvia, J. Electronal. Chem.. 347 (1994) 237.

[21] P. Carro, S.L. Marchiano. A. Hernández Creus, S. González, R.C. Salvarezza and A.J. Arvia, Phys. Rev. E. 48 (1993) 2374.

[22] P. Meakin. P. Ramanlal, L.M. Sander and R.C. Ball, Phys. Rev. A. $34(1986) 509$

[23] P. Herrasti. P. Ocón, L. Vázquez. R.C. Salvarezza, J.M. Vara and A.J. Arvia, Phys. Rev. A, 4.5 (1992) 7740 . 